\title{
COMPREENSÕES DE LIDERANÇA PELA EQUIPE DE ENFERMAGEM
}

\author{
Taysa Dal Piva Vieira ${ }^{1}$, Rogério Dias Renovato², Cibele de Moura Sales ${ }^{3}$
}

\begin{abstract}
RESUMO: A proposta deste estudo foi compreender as experiências da equipe de enfermagem sobre a liderança, enfocando situações nas quais foram líderes e quando foram liderados. Trata-se de pesquisa qualitativa, na qual a Fenomenologia Social de Alfred Schutz foi adotada como aporte teórico. Os participantes da pesquisa foram 10 componentes da equipe de enfermagem vinculados a hospital geral de médio porte. A captação das falas foi por meio de entrevista fenomenológica e semiestruturada, tendo como questões norteadoras: Como é liderar para você e como é ser liderado? Com o desvelar do fenômeno emergiram três unidades de significado: Características do líder, Experiência profissional e Relação líder e liderado. A experiência profissional e as relações interpessoais interferem na liderança, porém cabe ao enfermeiro desenvolver a capacidade de liderar, tendo conhecimento suficiente para defrontar essas situações e, através delas, conseguir estabelecer o seu lugar dentro da equipe. DESCRITORES: Liderança; Administração hospitalar; Equipe de enfermagem.
\end{abstract}

\section{THE NURSING TEAM'S UNDERSTANDINGS OF LEADERSHIP}

ABSTRACT: This study proposed to investigate the nursing team's experiences on leadership, focussing on situations in which they were leaders, and in others when they were led. It is qualitative research in which Alfred Schutz's Social Phenomenology was adopted as a theoretical contribution. The participants in the research were 10 members of the nursing team linked to a medium-size general hospital. The discourses were gathered by means of a phenomenological and semi-structured interview, with the guiding questions: What is leading like for you, and what is it like to be led? As the phenomenon was revealed, three units of meaning emerged: The characteristics of the leader, Professional experience, and The leader/led relationship. Professional experience and interpersonal relationships influence leadership, but it falls to the nurse to develop leadership ability, having sufficient knowledge to face these situations and, through them, to manage to establish his or her position within the team. DESCRIPTORS: Leadership; Hospital administration; Nursing team.

\section{COMPRENSIONES DE LIDERAZGO POR EL EQUIPO DE ENFERMERÍA}

RESUMEN: La propuesta de este estudio fue comprender las experiencias del equipo de enfermería acerca del liderazgo, enfocando situaciones en las cuales fueron líderes y cuando fueron liderados. Es una investigación cualitativa, en que la Fenomenología Social de Alfred Schutz fue adoptada como aporte teórico. Participaron de la investigación 10 integrantes del equipo de enfermería vinculados al hospital general de medio porte. Las hablas fueron captadas por medio de entrevista fenomenológica y semiestructurada y las cuestiones norteadoras fueron: ¿Cómo es, para usted, liderar? ¿Y como es ser liderado? Con el desvelar del fenómeno, resultaron tres unidades de significado: Características del líder, Experiencia profesional y Relación líder y liderado. La experiencia profesional y las relaciones interpersoales interfieren en el liderazgo, pero es papel del enfermero desarrollar la capacidad de liderar, presentando conocimiento suficiente para lidiar con esas situaciones y, por medio de ellas, lograr establecer su sitio en el equipo. DESCRIPTORES: Liderazgo; Administración hospitalar; Equipo de enfermería.

${ }^{1}$ Enfermeira. Especialista em Acupuntura.

${ }^{2}$ Farmacêutico. Doutor em Educação. Professor do Curso de Graduação em Enfermagem da Universidade Estadual de Mato Grosso do Sul - UEMS.

${ }^{3}$ Enfermeira. Doutora em Ciências da Saúde. Professora do Curso de Graduação em Enfermagem da UEMS. 


\section{INTRODUÇÃO}

A trajetória histórica da liderança na Enfermagem tem sofrido transformações em decorrência dos avanços tecnológicos, de novas exigências profissionais, sem contar com a inserção do enfermeiro em outros cenários de práticas. Além dos espaços tradicionais, como hospitais e clínicas, mas avança no campo da Saúde Coletiva, e ali exerce suas atribuições de gestor, educador e de assistência.

Os modelos de liderança dependem não apenas de questões estruturais, mas da equipe de trabalho que compõem o quadro da enfermagem. A relação do enfermeiro com sua equipe requer a participação de todos, ao mobilizar relações de poder, e estabelecer possibilidades de comunicação e reflexão no cotidiano dos profissionais da enfermagem, ou seja, trata-se de um processo coletivo e participativo ${ }^{(1)}$.

O enfermeiro desempenha papel de gestor em vários serviços de saúde, sendo o responsável pela administração e organização de unidades, escala de funcionários, provisão de recursos materiais, além da supervisão das técnicas rotineiras de enfermagem. Entretanto, a liderança sobrepõe-se a essa gerência, já que nem todo chefe é líder, mesmo que seja algo esperado. O exercício da liderança envolve comportamentos, tais como, a capacidade de influenciar as pessoas, e a adoção de atitudes que evocam empatia sobre seus supostos liderados ${ }^{(2)}$.

A posição de liderança do enfermeiro diante de sua equipe não lhe garante o poder de um líder. A liderança de um grupo não se concretiza apenas diante de cargos institucionalizados, e não está legitimada somente por um organograma. Esta é processual, apreendida e construída na relação com os seus liderados, que atribuem requisitos indispensáveis para o enfermeiro-líder, dentre eles, confiança, credibilidade, lealdade e comprometimento com sua equipe ${ }^{(3)}$.

Em relação à equipe de enfermagem, as percepções sobre a liderança podem estar atreladas à figura do líder autoritário, que se posiciona hierarquicamente, tomando para si a centralidade das decisões. Esse estilo de liderança ainda pode ser predominante nos serviços de saúde, e está pautado no modelo normativo de planejamento. Esse perfil de líder parece receber críticas, já que leva em conta apenas uma única verdade identificada pelo enfermeiro-gestor, a negação de outros sujeitos e resistências, bem como a exclusão de outras dimensões mais democráticas e participativas $^{(4)}$.
O exercício da liderança do enfermeiro requer foco e competência para orientar seus liderados. Com isso, é possível estabelecer uma relação de confiança e respeito, provocando motivação do grupo. Essa relação aumenta o comprometimento e melhora a qualidade da assistência ${ }^{(5)}$.

Essa investigação pretende contribuir para a prática em enfermagem ao abordar a temática liderança em um contexto de novos desafios e maior complexidade do cuidado em saúde. Diante disto, o objetivo da pesquisa foi compreender as experiências da equipe de enfermagem sobre a liderança, enfocando situações nas quais os componentes da equipe - auxiliares, técnicos e enfermeiros - foram líderes e quando foram liderados.

\section{MÉTODO}

Trata-se de pesquisa de cunho qualitativo, descritiva e exploratória realizada em 2010. A população de estudo foi a equipe de enfermagem de um hospital de médio porte, geral, filantrópico, responsável por 65 leitos, situado em município na região sudoeste do Estado de Mato Grosso do Sul. A equipe de enfermagem era composta por 46 funcionários entre técnicos e auxiliares e quatro enfermeiros.

A pesquisa foi inicialmente apresentada à direção do hospital, que autorizou a realização do estudo. O contato com os participantes deu-se no próprio local de serviço. Depois, foi realizada reunião com os enfermeiros, os quais entraram em contato com suas equipes, relatando a investigação e fazendo o convite para participar. Após isso, uma das pesquisadoras contatou os demais participantes da pesquisa, formalizando o convite. Em caso de aceite, foi agendado o encontro em uma das salas da instituição, sendo o projeto devidamente explicado e, somente após a assinatura do termo de consentimento, foi iniciada a entrevista. Foram incluídos apenas profissionais com vínculo empregatício no hospital, os quais exerciam função de técnico em enfermagem, auxiliar de enfermagem ou enfermeiro e que assinaram o termo de consentimento livre e esclarecido.

A definição do número de participantes deu-se por saturação, que totalizaram 10 profissionais da enfermagem; a saturação ocorreu no momento em que não foram obtidas novas informações em relação ao objeto de estudo, como falas e situações repetitivas, não implicando em mudanças na análise ${ }^{(6)}$.

Os dados foram coletados no período através da entrevista fenomenológica e semiestruturada, na qual foram utilizadas perguntas disparadoras "Como é para 
você vivenciar o fenômeno da liderança, quando você lidera? E quando você é liderado?” As entrevistas foram realizadas em sala reservada, sendo gravadas e posteriormente transcritas. Os participantes da pesquisa foram identificados com códigos, sendo a letra $\mathrm{E}$ para enfermeiros, e a letra L, para auxiliares e técnicos, assegurando o anonimato dos entrevistados.

A análise das entrevistas ocorreu inicialmente através de leitura completa do material transcrito, tendo como objetivo apreender os significados dos sujeitos a respeito da liderança. Em seguida, foram lidos novamente os relatos, buscando identificar unidades de significado. E por fim, a síntese dos achados culminou em descrição do fenômeno interrogado ${ }^{(7)}$.

A fundamentação teórica foi a Fenomenologia Social de Alfred Schutz, abordagem descrita como ciência reflexiva, de profundidade filosófica, na qual a essência está em captar o fenômeno vivido e não somente o fato. A Fenomenologia pretende desvelar a vivência do ser social inserido dentro de um mundo social, cultural, histórico e natural, no qual os fatos são constituídos através de toda sua vivência e da vivência dos seus semelhantes ${ }^{(8)}$.

A fim de compreender a vida cotidiana, existem conceitos que nos remetem ao ser social: a situação é o lugar que o ser ocupa dentro da sociedade, em que exerce seu papel ético, religioso, intelectual, político. A experiência biográfica significa que o ser está situado em um lugar biográfico no mundo da vida e ali ele pensa, sente e age. E por último o estoque de conhecimento gerado pelas experiências tanto próprias quanto de outros levarão o ator social à interpretação do mundo e consequentemente, ao desenvolvimento de suas ações ${ }^{(9)}$.

A Fenomenologia Social de Alfred Schutz tem sido empregada na Enfermagem por possibilitar apreender as vivências do cotidiano profissional, bem como trazer as inter-relações das pessoas no mundo da vida, entremeados com o mundo social. Esses espaços de intersubjetividade permitem conhecer os significados das relações sociais, as quais apresentam características próprias de cada ação, como é o caso das situações de liderança de enfermagem, em que cada ação pode ocorrer de maneira consciente, intencional, sendo dotadas de sentidos para o ser social, como o auxiliar, o técnico e o enfermeiro em um determinado contexto, nesse caso, o cenário hospitalar ${ }^{(10)}$.

Para a realização dessa investigação, foram respeitados os procedimentos éticos exigidos pela Resolução 196/96, do Conselho Nacional de Saúde. A pesquisa foi submetida ao Comitê de Ética de Pesquisa em Seres Humanos da Universidade Federal do Mato Grosso do Sul, sendo o protocolo de aprovação número 1702/2010.

\section{RESULTADOS}

Os participantes foram caracterizados segundo as seguintes variáveis: idade, sexo, escolaridade, categoria profissional, tempo de formação na área, tempo de trabalho na instituição, carga horária diária e setor do hospital.

Dos entrevistados cinco tinham idade entre 20 a 30 anos, três de 30 a 40 anos e dois de 40 a 50 anos de idade. Nove eram do sexo feminino, e apenas um do sexo masculino. Todos concluíram o ensino médio, três têm curso superior completo e três possuem curso superior incompleto. Três são enfermeiros, seis técnicos em enfermagem e um auxiliar de enfermagem. Quanto ao tempo de formação na área, um tinha menos de um ano; quatro, um ano e meio a três anos; três com três anos e meio a cinco anos de experiência; e dois possuíam mais de 15 anos de formação.

Em relação ao tempo de trabalho no hospital estudado, dois atuavam há menos de um ano, seis de um a três anos, um cinco anos e um mais de 20 anos. A carga horária predominante foi de seis horas diárias. Três trabalhavam na maternidade e centro cirúrgico, dois do setor de internação, dois eram responsáveis pela supervisão geral do hospital, um da central de materiais esterilizados, um da pediatria e um da administração (Tabela 1).

Após a caracterização dos entrevistados passou-se para a interpretação das descrições, emergindo três unidades de significado, a seguir apresentadas.

\section{Características do líder}

Nesta unidade de significado podem-se desvelar algumas habilidades e características que segundo os profissionais de enfermagem, são essenciais para o exercício da liderança. Dentre elas destaca-se o papel do líder em instruir a equipe, servindo como fonte de aprendizagem.

Duas entrevistadas definem que instruir o funcionário é, ou deveria ser, uma das características inerentes ao líder:

É bom ter uma pessoa prá te orientar, prá te ajudar. (L5)

[...] quem deveria estar aqui auxiliando, ensinando as coisas prá essa pessoa que entrou, seriam eles. (L8) 
Tabela 1- Distribuição dos participantes do estudo segundo as características sociodemográficas. Mato Grosso do Sul, 2010

\begin{tabular}{|c|c|c|c|c|c|c|c|}
\hline Participante & Sexo & $\begin{array}{l}\text { Idade } \\
\text { (anos) }\end{array}$ & Escolaridade & $\begin{array}{l}\text { Tempo de } \\
\text { formação } \\
\text { (anos) }\end{array}$ & $\begin{array}{c}\text { Carga } \\
\text { horária } \\
\text { diária }\end{array}$ & Setor & $\begin{array}{c}\text { Tempo de } \\
\text { trabalho na } \\
\text { instituição } \\
\text { (anos) }\end{array}$ \\
\hline E1 & F & 24 & $\begin{array}{l}\text { Superior } \\
\text { completo }\end{array}$ & $<1$ & $6 \mathrm{~h}$ & $\begin{array}{l}\text { Supervisão } \\
\text { geral }\end{array}$ & $<1$ \\
\hline E2 & F & 31 & $\begin{array}{l}\text { Superior } \\
\text { completo }\end{array}$ & 3 & $6 \mathrm{~h}$ & Administração & 2 \\
\hline E3 & F & 27 & $\begin{array}{l}\text { Superior } \\
\text { completo }\end{array}$ & 2 & $8 \mathrm{~h}$ & $\begin{array}{l}\text { Maternidade e } \\
\text { Centrocirúrgico }\end{array}$ & 1 \\
\hline L4 & F & 26 & $\begin{array}{l}\text { Ensino médio } \\
\text { completo }\end{array}$ & 4 & $6 \mathrm{~h}$ & Pediatria & 1,5 \\
\hline L5 & $\mathrm{F}$ & 34 & $\begin{array}{l}\text { Ensino médio } \\
\text { completo }\end{array}$ & 4 & $6 \mathrm{~h}$ & Internação & $>1$ \\
\hline L6 & $\mathrm{F}$ & 28 & $\begin{array}{l}\text { Ensino superior } \\
\text { incompleto }\end{array}$ & 3 & $6 \mathrm{~h}$ & $\begin{array}{l}\text { Central de } \\
\text { esterilização } \\
\text { de materiais }\end{array}$ & 2 \\
\hline L7 & $\mathrm{F}$ & 47 & $\begin{array}{l}\text { Ensino médio } \\
\text { completo }\end{array}$ & 18 & $8 \mathrm{~h}$ & $\begin{array}{l}\text { Maternidade e } \\
\text { Centrocirúrgico }\end{array}$ & 5 \\
\hline L8 & $\mathrm{F}$ & 24 & $\begin{array}{l}\text { Ensino superior } \\
\text { incompleto }\end{array}$ & 4 & $6 \mathrm{~h}$ & Internação & 2 \\
\hline L9 & M & 39 & $\begin{array}{l}\text { Ensino superior } \\
\text { incompleto }\end{array}$ & 2 & $6 \mathrm{~h}$ & $\begin{array}{l}\text { Sup ervisão } \\
\text { geral }\end{array}$ & 2 \\
\hline L10 & $\mathrm{F}$ & 42 & $\begin{array}{l}\text { Ensino médio } \\
\text { completo }\end{array}$ & 22 & $8 \mathrm{~h}$ & $\begin{array}{l}\text { Maternidade e } \\
\text { Centrocirúrgico }\end{array}$ & 22 \\
\hline
\end{tabular}

Outra característica revelada nos depoimentos foi o trabalho em equipe, em que a equipe de enfermagem expõe o desejo que seu líder seja um aliado do trabalho, não apenas desempenhando função de chefia, coordenação, organização e planejamento, mas atuando na assistência direta ao paciente:

[...] aqui a gente tem enfermeiros que são bem participantes, eles vem aqui, ajudam, vão nos quartos [...]. (L8)

[...] ser companheiro, atencioso [...] é ser um bom líder. (L5)

A responsabilidade atribuída ao líder foi evidenciada por vários entrevistados, acreditando que, por questões de hierarquia institucional e vertical, o enfermeiro seria o responsável pelas ações dos técnicos e auxiliares de enfermagem, diminuindo a sobrecarga e a pressão existente na categoria, e evidenciando a valorização da equipe. As falas a seguir revelam isso:
Quando eu entrei aqui, elas estavam sem chefia na época, por um lado foi bom, porque tinha alguém prá defender elas. (E3)

[...] assim, trabalhando em grupo, é melhor, porque não é tanta responsabilidade nas minhas costas. (L5)

A comunicação foi outra característica apontada, em que o liderado muitas vezes necessita ser ouvido, a fim de buscar apoio e estabelecer ligação estreita entre os dois. Conforme exposto em alguns relatos:

[...] de sentar, de conversar, de ser amigo e profissional ao mesmo tempo [...]. (L8)

[...] sempre do teu lado, te ouvindo, te ajudando, isso que é ser um bom líder. (L5)

[...] se você sentar e conversar e colocar os pontos negativos eles vão te escutar. (L4) 
Dois auxiliares de enfermagem apontaram que além de todas essas características existem traços natos em sua personalidade que o tornam apto à função. Nesse contexto, as falas dos auxiliares revelam a referência cotidiana social que eles têm de líderes:

[...] tem que ter uma pessoa com espírito de liderança, para que as coisas se desenvolvam melhor. [...] porque eu acho assim, que tá dentro de cada um, ser líder está dentro do caráter de cada pessoa. (L7)

[...] ter aptidão prá ser líder, se não você não consegue conduzir satisfatoriamente a equipe e o hospital. (L9)

\section{Experiência profissional}

Entre os pesquisados, verificou-se que os enfermeiros apresentam tempo de formação inferior a três anos, o que pode gerar insegurança diante da equipe que lidera, como revelado nos depoimentos:

[...] trabalhar com equipe antiga [pausa] eu, recém formada, é bem complicado. (E3)

[...] quando os profissionais são mais antigos, de mais idade, pelo fato de você ser mais nova, então sempre tem aquela resistência. (E2)

[...] eu sou a mais nova, eu terminei a faculdade ago$\mathrm{ra}$. A questão de você ter que liderar, principalmente pessoas mais velhas, é difícil! (E1)

A equipe de técnicos e auxiliares de enfermagem, com seus anos de experiência profissional, ao se apoiar na sua longa trajetória pode assumir o papel de líder. Dessa forma, entram em colisão com os enfermeiros recém-formados e os subalternizam, como evidenciado:

[...] quando entra gente nova, então, aí você, sendo a mais antiga do setor, sabendo, conhecendo a rotina do setor, você tem que dividir as tarefas, ensinar como que funciona isso, como que funciona aquilo, pra poder trabalhar bem [...]. (L8)

[...] assim, eu acho que sou líder pela minha experiência, trabalho, pela minha prática dia a dia, pelo meu conhecimento, sendo técnico na minha profissão, às vezes eu chego a chefiar pelo fato, assim, de eu trabalhar com pessoas que são novas na profissão, que depende de um pouco mais de conhecimento $e$ experiência [...]. (L7)

[...] eu acho que eu lidero, eu ajudo, eu ensino, então acho que assim, você lidera, você conhecendo o setor, conhecendo o trabalho [...]. (L10)

[...] toda vez que não tem enfermeira aqui a gente trabalha assim, a gente trabalha bem, porque a gente é aceita pela unidade, pelo setor. Então, não tenho dificuldade como líder da unidade. (L10)

\section{Relação líder e liderado}

As relações de vínculo que os enfermeiros tentam estabelecer com a equipe de enfermagem são descritas a seguir:

[...] eu nunca cheguei em uma pessoa e disse'você vai fazer isso', eu sempre chegava e falava 'você pode fazer isso?'. Sempre pedindo 'por favor', e com isso eu consegui ter mais acesso. (E2)

\section{[...] funcionário você tem que conquistar, né?} (E1)

O vínculo com o liderado pode ser desenvolvido pelo enfermeiro através de ligação empática. É através dessa ligação que ele segue na tentativa de não desfazer a relação benéfica ao trabalho. $O$ enfermeiro deve entender o outro como único em sua individualidade; assim para entendê-lo é necessário assumir relações de intersubjetividade permitindo compreender o outro em seu mundo vivido, atentando para suas subjetividades como constitutivas das relações sociais.

Diante da relação interpessoal, os liderados apontam que o respeito e confiança de seus lideres é um fator primordial nas relações. Esse fenômeno é desvelado pelas falas:

[...] ela me respeita, respeita meu espaço, ela me respeita assim como profissional, e eu também como ela [...]. (L4)

\section{[...] eles confiam no nosso trabalho [...]. (L6)}

[...] peço as coisas com educação, acho que isso é fundamental. (L6)

[...] tem jeito prá pedir as coisas, ter um bom relacionamento. (L8) 


\section{DISCUSSÃO}

A condução dos serviços de enfermagem e a educação permanente da equipe é uma das principais tarefas do enfermeiro. Logo, saber guiar com qualidade e promover eficiência constituem-se características vinculadas a esse profissional, e estão diretamente associadas à liderança. Na condução do pessoal, o enfermeiro fica ciente de sua responsabilidade com o trabalho e da necessidade de promoção de bem-estar entre os colegas, a fim de melhorar o atendimento ao paciente, bem como estabelecer uma relação de reciprocidade de perspectivas ${ }^{(7)}$.

A disposição para aprender após o processo de formação inicial precisa estender-se à equipe de enfermagem que percebe a importância e relevância do enfermeiro como educador. Com isso seria possível amenizar as condições atuais do trabalho da enfermagem, geralmente compartimentalizado e de enfoque tecnicista. Desse modo, a educação permanente pode contribuir na promoção da qualidade de vida aos trabalhadores, desencadear maior qualificação profissional, o que levará à melhor assistência à população ${ }^{(11)}$.

A figura do enfermeiro como líder e educador apoia-se no fato de ser visto como profissional de referência para os componentes de sua equipe, que por sua vez, precisa buscar contínua atualização dos seus conhecimentos. Desse modo, a liderança exercida pelo enfermeiro pode implicar em outras dimensões, como a de agente multiplicador de saberes. Ou seja, aquele que socializa o conhecimento amealhado ao longo de sua vida, e proporciona o desenvolvimento de potencialidades entre seus liderandos, visto que as pessoas apresentam uma bagagem de conhecimentos provenientes do contexto social e de suas próprias experiências ${ }^{(7,12)}$.

A responsabilidade pode ser uma das atribuições do líder, entretanto a eficiência na comunicação é a ferramenta imprescindível ao desenvolvimento da liderança. Portanto, quanto mais orientada para o futuro, mais flexível e distante do papel controlador e ditador de regras ${ }^{(13)}$. Os entrevistados acreditam que o líder deve estar disposto para ouví-los. Eles esperam diretrizes vindas de seu condutor, isto é, algo melhor do que eles poderiam fazer ou pensar. Logo, a liderança parece envolver atitudes e ações de pessoas entre si, permeadas em uma relação de intersubjetividade de $\operatorname{motivos}^{(7)}$.

Todavia, concepções de que a liderança é característica inerente do indivíduo ainda se fizeram presen- tes nas falas dos entrevistados e estão vinculadas às primeiras abordagens sobre o que é ser líder. Porém, na contemporaneidade, tem-se atentado para o fato de que é possível desenvolver a liderança. Desse modo, o enfermeiro pode tornar-se líder e desenvolver habilidades e competências, que se iniciam já na sua formação, e continuam em sua vida profissional ${ }^{(3-4)}$.

Em consequência disso, estudo realizado com enfermeiros recém-formados apontou que fatores relacionados à liderança são os de maior dificuldade no mercado de trabalho. Possivelmente, decorrentes da fraca correlação entre os conteúdos ministrados na graduação e sua aplicação. Uma das possíveis causas dessa desarticulação seria a pouca ênfase da temática liderança nos cursos de graduação ${ }^{(14)}$. Isto configura um aprendizado com enfoque técnico, e que não prioriza o ensino de caráter critico e reflexivo.

Conforme relata pesquisa realizada no Rio Grande do Sul, os estudantes parecem desvalorizar os aspectos relacionados à liderança, que só é lembrada, quando esses, já formados, defrontam-se com conflitos e precisa coordenar indivíduos com mais idade e experiência ${ }^{(15)}$.

Além disso, a falta de experiência profissional parece ser agravada pelo fato de muitos técnicos e auxiliares apresentarem considerável tempo de serviço; delimitando com clareza seus territórios de poder. E assim estabelecem estratégias de resistência e enfrentamento frente à liderança de enfermeiros novatos ${ }^{(16)}$. Desse modo, a insegurança relatada em algumas falas pode influenciar e interferir negativamente na possibilidade de liderar a equipe de enfermagem. Essa postura é considerada como um dos elementos desfavoráveis à liderança eficaz. Por outro lado, se o enfermeiro demonstra segurança, tem boa argumentação, apresenta firmeza nas decisões e expõe de modo claro suas convicções, tais atitudes podem favorecer a sua posição junto à equipe ${ }^{(3)}$.

Nessas situações permeadas de relações de poder, preconiza-se a inserção da liderança dialógica, conforme a perspectiva freireana, como instrumento de trabalho para promover mudanças nesses microespaços. E assim oportunizar ações comunicativas mais eficientes, estimulando a autonomia e valorização dos componentes da equipe ${ }^{(12)}$.

O processo de liderar envolve os dois componentes - o líder e o liderado. O vínculo pode ser obtido pela valorização e compreensão de seus pontos de vista, já que cada um dos sujeitos vivencia essa situação conforme sua própria experiência, estabelecendo intercâmbio de perspectivas subjetivas ${ }^{(7)}$. Portanto, torna-se necessário 
conhecer e desenvolver sensibilidade interpessoal com intuito de apreender as expectativas do outro ${ }^{(17)}$.

No entanto, em pesquisa realizada em hospital na cidade de São Paulo apontou problemas interpessoais com impacto negativo entre a equipe, dentre eles, ausência de elogios dos líderes para os liderados, ausência de críticas construtivas a respeito do desempenho, não reconhecimento do trabalho realizado e falta de transparência na comunicação. Esses aspectos verificados parecem comprometer o trabalho coletivo, que deve ser incentivado pela liderança ${ }^{(17)}$.

Para que haja o respeito mútuo de cada classe profissional, é necessário conhecer e entender as atribuições de cada membro da equipe, o mundo no qual o sujeito está inserido. Ou seja, aproximar-se do seu mundo vivido e compreender as influências que integram suas biografias ${ }^{(7)}$. Assim, nas relações interpessoais, o respeito funciona como uma base sólida, sendo um aspecto indispensável quando se pensa em liderança ${ }^{(11)}$.

\section{CONCLUSÃO}

Os significados desvelados nas falas dos participantes da pesquisa mostraram que são necessárias certas habilidades para a liderança em enfermagem. Entre elas destacam-se a capacidade de ensinar o liderado na realização das competências de enfermagem; o desenvolvimento da comunicação eficaz e o exercício da responsabilidade por seus liderados. Os traços natos não apareceram na maioria das falas, o que mostra que essa percepção vem se apagando. Desse modo, as pessoas percebem que as características do líder podem ser desenvolvidas ao longo de sua vida cotidiana e sua experiência de vida.

A experiência profissional e as relações interpessoais interferem na liderança, porém cabe ao profissional enfermeiro desenvolver a capacidade de liderar, tendo conhecimento suficiente para defrontar essas situações e, através delas, conseguir estabelecer o seu lugar dentro da equipe.

Espera-se que as vivências desses profissionais, relatadas neste estudo, contribuam para o pensar sobre liderança, visto que essa temática é pouco abordada em estudos sob a perspectiva de abordagens compreensivas, como a Fenomenologia. Além do mais, a investigação científica sobre a liderança em enfermagem espera potencializar e qualificar o cuidado exercido em sua prática profissional nos cenários de saúde, ampliar e consolidar suas perspectivas de atuação, e assim auxiliar nas transformações do mundo do trabalho, levando em conta os sujeitos envolvidos nesses espaços de intersubjetividade.

\section{REFERÊNCIAS}

1. Balsanelli AP, Cunha ICKO. Liderança no contexto da enfermagem. Rev Esc Enferm USP. 2006;40(1):117-22.

2. Moura GMSS, Magalhaes AMM, Dall'agnol CM, Juchem BC, Marona DS. Liderança em enfermagem: análise do processo de escolha das chefias. Rev. LatinoAm. Enfermagem. 2010;18(6):1099-106.

3. Simões LA, Fávero N. O desafio da liderança para o enfermeiro. Rev. Latino-Am. Enfermagem. 2003;11(5):567-73.

4. Lanzoni GMM, Meirelles BHS. Liderança do enfermeiro: uma revisão integrativa de literatura. Rev. Latino-Am. Enfermagem. 2011;19(3):651-8.

5. Alecrim JS, Campos LF. Visão dos técnicos e auxiliares de enfermagem sobre o estilo de liderança do enfermeiro. Cogitare enferm. 2009;14(4):628-37.

6. Fontanella BJ, Ricas J, Turato ER. Amostragem por saturação em pesquisas qualitativas em saúde: contribuições teóricas. Cad. Saúde Pública. 2008;24(1):17-27.

7. Merighi MAB, Praça NS. Abordagens teóricometodológicas qualitativas da mulher no período reprodutivo. Rio de Janeiro: Guanabara Koogan; 2003.

8. Capalbo C. Metodologia das ciências sociais: a fenomenologia de Alfred Schutz. Rio de Janeiro: Antares; 1979.

9. Minayo MCS. O desafio do conhecimento: pesquisa qualitativa em saúde. 10ª ed. São Paulo: Hucitec; 2007.

10. Chubaci RYS, Merigui MBA, Yasumuri Y. A mulher japonesa vivenciando o câncer cérvico uterino: um estudo de caso com a abordagem da fenomenologia social. Rev Esc Enferm USP. 2005;39(2)189-94.

11. Amestoy SC, Cestari ME, Thofehrn MB, Milbrath VM. Características que interferem na construção do enfermeiro-líder. Acta Paul. Enferm. 2009;22(5):673-8.

12. Amestoy SC, Trindade LL, Waterkemper R, Heldman ITS, Boehs AE, Backes VMS. Liderança dialógicanasinstituições hospitalares. Rev Bras Enferm.. 2010;63(5):844-7. 
13. Ribeiro M, Santos SL, Meira TGBM. Refletindo sobre liderança em enfermagem. Esc. Anna Nery. 2006;10(1):109-15.

14. Dias AO, Guariente MH, Belei RA. O enfermeiro recém-graduado e o primeiro emprego. Percepções da formação na graduação e da atuação profissional. Arq. Ciênc. Saúde Unipar. 2004;8(1):19-24.

15. Amestoy SC, Cestari ME, Thofehrn MB, Milbrath VM, Trindade LL, Backes VML. Processo de formação de enfermeiros líderes. Rev Bras Enferm. 2010;63(6):940-5.

16. Vilela PF, Souza AC. Liderança: um desafio para enfermeiro recém-formado. Rev. enferm. UERJ. 2010;18(4):591-7.

17. Santos KMAB, Silva MJP. Comunicação entre líderes e liderados: visão dos enfermeiros. Rev Esc Enferm USP. 2003;37(2):97-108. 